\title{
The Anatomy of the Scutellum in Zea Maïs.
}

\author{
BY
}

ETHEL SARGANT AND AGNES ROBERTSON, B.SC.

\section{With Plate V.}

BOTANISTS have long been familiar with the external structure of $B$ the Grass-embryo, which is sufficiently different from that of the embryo in other Monocotyledons to leave some doubt as to the homology of their parts. We began the examination of several Grass seedlings in the autumn of 1902, hoping that their anatomy at a period soon after germination might throw light on this vexed question. We did not propose to monograph the family from this point of view, but, having chosen a few genera from very different parts of it, to compare their seedlings anatomically with each other, and with those of the Monocotyledons already worked out by one of us.

Even this skeleton scheme has not yet been completed, for we have not succeeded in getting all the material desirable. Side issues of some importance have been raised, however, and in particular the anatomical structure of the Maize scutellum offers some features of interest which we believe to be still undescribed ${ }^{1}$. They are clearly bound up with its function as a sucking organ, and the subject is thus a digression from the main morphological line of research, and is more conveniently treated in a separate form.

\section{EXTERNAL MORPHOLOGY OF EMBRYO.}

Within the ripe fruit the main axis of the embryo is triply protected. Embryo and endosperm alike are enclosed in the dry covering of the grain. When a part of this is removed, the whole embryo is seen lying against one face of the endosperm (Fig. 3, Pl. V, cf. also Figs. 1 and 6). The second covering is formed of the scutellum (sc. in Figs. I, 5, 7), a cushionlike structure which is wrapped round the embryonic axis and still conceals the greater part of it in the first days of germination (Fig. 3).

1 Ethel Sargant and Agnes Robertson, 'On some Anatomical Features of the Scutellum in Zea Maïs.' Report Brit. Assn., Southport, 1903, p. 860.

[Annals of Botany, Vol. XIX. No. LXXIII. January, 1905.] 
Finally, each growing-point has its own sheath: the coleoptile encloses the plumule ( $c l$. in Fig. I), and the coleorhiza the radicle ( $c r$. in Figs. I-6). The insertion of these sheaths on the axis, and of the axis on the scutellum, is shown in Fig. $I$.

The coleoptile is sharply pointed and stiffened on either side by a vascular bundle. It protects the young stem until the whole shoot is clear of the soil, and is sometimes over an inch long. The rolled-up leaves of the stem-bud finally break through the coleoptile, near the apex but a little to one side of it.

In Fig. 2 the root-sheath or coleorhiza is seen emerging from the covering of the grain. It never attains the length of the stem-sheath, and is soon penetrated by the primary root. Though less differentiated than the coleoptile it is a true sheath, and not a mere mass of tissue within which the radicle is formed endogenously.

The primary root (R, Figs. I and $6, \mathrm{Pl}$. V) grows vigorously when once started, and continues for many weeks to be the chief root-organ of the seedling. Two cauline roots appear very early between the scutellum and the young stem $\left(r^{\prime} r^{\prime}\right.$ in Figs. $\left.6,7,8,9\right)$. They are symmetrically placed on either side of a median section through the whole embryo, such as that shown in Fig. I on Plate V, and accordingly their insertion only $\left(r^{\prime}\right)$ is shown in that figure. They grow upwards, appearing over the top of the scutellum a few days after germination (Fig. 9). These twin roots break through the tissues of the young stem just at the base of the cleft dividing it from the upper part of the scutellum (Fig. 6). They press against the inner face of the scutellum in growing upwards, and the first effect of their growth is to widen this cleft by pressing the stem-bud outwards (Figs. 5 and 6). This mechanism no doubt aids the ascending axis to get clear of the seed, and it is possible that the cleft itself-which in the damp soil is sure to be filled with water-may be useful as a reservoir, tapped for a few days by the twin roots as they lengthen.

The twin roots curve sharply downwards so soon as they are clear of the seed and enter the soil, where, like other cauline roots, they serve as auxiliaries to the main root. When growing Maize in pots in a greenhouse, we often observed the seed with the lengthening stem-bud attached to be raised above the surface of the soil on a tripod formed of the primary root and the twin cauline roots. This recalls the stilt-roots of Pandanus ${ }^{1}$. But we do not know whether the habit is characteristic of Maize germinating under natural conditions.

The shape and position of the scutellum are shown in Figs. I, 3, 4, 5 and 6 on Pl. V (cf. also Figs. 7-10). It is in contact with the endosperm over almost the whole of its dorsal surface. It supplies food to other

\footnotetext{
1 Kerner and Oliver, 'The Natural History of Plants,' vol. i, p. $75^{6 .}$
} 
parts of the embryo from the stores laid up in its own tissues, and from those of the endosperm. The contents of the endosperm are by degrees dissolved and absorbed by the scutellum, which transmits them in solution to the growing parts of the embryo.

\section{EPITHELIUM AND GLANDS.}

The epidermis of the embryo is of normal structure except on the dorsal face of the scutellum. Wherever this face is in contact with the endosperm, that is over the whole of it with the exception of the extreme base and a small area corresponding to the insertion of the pedicel, it is covered with a well-marked epithelium. This tissue has often been described, and is shown in our Figs. $16,17,18$.

The scutellum is always more or less wrinkled on its dorsal face. The outline of this face is marked in section by a nearly continuous dark line of varying thickness (Fig. I7), and the wrinkles are seen as depressions, sometimes filled with a dark mass. This appearance is no doubt due to a viscous secretion from the epithelium cells, which covers their free surface with a thin sticky layer and sometimes collects in the wrinkles like water in a furrow. We have seen it most clearly in preparations cut from an embryo which had been dissected from the ungerminated seed and fixed in methylated spirit (Fig. I3). In this specimen the secretion, whatever its nature, has been exposed to the solvent action of alcohol only, whereas all the other preparations figured are cut from germinating seeds, in which the tissues were of course thoroughly pene. trated with water before they were plunged in alcohol. The depressions in the dorsal outline of the scutellum are also deeper and more numerous in sections from the ungerminated embryo than in those cut from seedlings in which germination has begun.

The epithelium is of course folded in on itself more or less sharply in each wrinkle, and the effect in section is that of a pit lined with epithelium cells and containing a dark mass of secretion (Fig. I3). But leading out of such furrows we sometimes find narrow clefts, also lined with epithelium and penetrating deeply into the tissues of the scutellum (Figs. II and I3).

In the ungerminated seed these clefts are already fully formed. They always contain a layer of secretion, but they are often so narrow that it appears in section as a dark line of no great thickness separating one surface of epithelium from the other.

The corresponding glands found in the scutellum of germinating embryos have commonly a very thin layer of secretion (Figs. II and I2), or it may be completely absent (Fig. 14). The two surfaces of epithelium then seem to be in contact. In such cases the secretion has no doubt been 
washed out by the water in which the tissues of the young seedling are soaked, and perhaps the internal tissues which lie round the gland have swollen, closing its narrow cleft and expelling the secretion at its mouth. Such swelling of internal tissues may also account for the comparative absence of wrinkles in the dorsal surface of the scutellum belonging to a growing embryo. In such embryos many glands open out on a smooth layer of epithelium, whereas in the dry seed we cut they nearly always started from the base of a depression.

The glands vary greatly in size. Some of the smallest are funnelshaped pits, others shallow slits, and it is very difficult to draw the line between structures which deserve the name of glands and mere depressions or wrinkles. The largest we measured were clefts of considerable size. The opening of one was $.66 \mathrm{~mm}$. long, and its maximum depth $\cdot \mathrm{I} \mathrm{mm}$. Another reached a depth of $.28 \mathrm{~mm}$.

The number of glands found in a single scutellum is also very variable. Three sets of our serial sections include the whole of the scutellum; and we have counted the number of glands in each series. The numbers thus obtained have no great absolute value. Two difficulties stand in the way of exact determination. The line between well-marked depressions and small glands is not easily drawn, and glands which run nearly parallel to the plane of section are readily passed over. The numbers recorded are therefore in all probability too small.

In seedling $A_{9}$ (Fig. 9, P1. V), six days old, the scutellum was cut transversely. Thirty-eight glands were counted.

In seedling $\alpha$, two days old, the scutellum was cut transversely. Only seven glands were found, all small. This is probably an exceptional case.

In seedling $b$, two days old, in which the scutellum was cut longitudinally, twenty-nine glands were counted.

Sections were also cut transversely through an imperfect scutellum, dissected out of an ungerminated seed. The extreme tip and extreme base were absent, but thirty-eight glands were counted in the remainder.

The majority of glands counted in those seedlings which were cut transversely run parallel with the longer axis of the scutellum, while in seedling $b$, which was cut longitudinally, the majority are more or less perpendicular to the longer axis. In other words, more glands were always counted in the direction perpendicular to the plane of section, and this reșult is clearly due to the difficulty of recognizing a gland which lies parallel to the section. But we believe that longitudinal glands are really rather more common than transverse ones.

The glands are scattered over the whole surface of the epithelium except where it covers the top of the scutellum. In seedlings $A_{9}, a$, and $b$, no glands are found above an imaginary line drawn across the scutellum at a distance from the apex of one-third its whole length. The apex of 
the scutellum is wanting in the fourth series of sections-that cut through the embryo of a dry seed-but glands are found near the beginning of this series, and they probably stand above the corresponding line. In all four series glands are more numerous in the middle zone than below it, but they are occasionally found even at the extreme base. They are also more frequent on the wings of the scutellum than on or very near the median spine (Figs. 6-8).

We have not followed the development of these glands, for they are fully formed in the ripe seed, which is the youngest stage we have examined. Their appearance in section suggests that they are infoldings of the epithelium.

\section{Vascular System of the Scutellum.}

The bundles of the scutellum are inserted on the stele of the axis at the great vascular junction on which the root-insertion $r^{\prime}$ is marked in Fig. I, P1. V. The bundle shown in that figure as entering the lower part of the scutellum is one of several large vascular branches which ramify there and supply its needs. There is no main bundle in this part of the scutellum, and the xylem of the various branches never becomes completely lignified.

A single massive bundle runs from the vascular junction into the upper part of the scutellum, and ends just below the extreme apex. This bundle, with its slender but numerous branches, constitutes the entire vascular system of the upper scutellum. A few days after germination its xylem is completely lignified, standing out sharply in stained sections.

Just above its insertion on the axis the main bundle is circular or oval in transverse section, and is surrounded by an unthickened endodermis. It lies near the ventral surface of the scutellum, towards which its small xylem group is directed. The phloem group is very large (Fig. I5). In the seedling figured there is hardly any indication of a division into two masses, but in others the two groups of phloem are quite clearly marked, and are partially divided from each other by a group of parenchymatous elements with wide lumen and slightly thickened walls which occupies the position of the sclerenchyma in the bundle of the mature stem. Such elements are present in the section drawn in Fig. 15 (scl.), but are not gathered up into a compact group.

The phloem proper or 'soft bast' does not show the regular geometrical pattern characteristic of the transverse section through a mature bundle.

Sections which cut the axis of the seedling transversely pass longitudinally through the main scutellum bundle as it enters the axis. Spiral and annular tracheids are the first xylem elements to be lignified. In a six days' seedling $\left(A_{9}\right.$, Fig. 9) many larger tracheids are also present, 
polygonal in transverse section ( $x$, Fig. 15$)$, and thickened in a rather irregular scalariform way.

Longitudinal sections through the phloem show the elements marked scl. in Fig. I 5 to be rather long cells with scanty contents and pitted walls not yet lignified. They clearly correspond to the sclerenchyma of the mature bundle.

The structure of the soft bast is shown in Fig. 19. The section drawn is one of a series cut longitudinally through a seedling only a few days after germination. Within the endodermis (end.) lie rows of long elements with much elongated nuclei $(s, s$, Fig. I9), which alternate-not very regularly-with rows of shorter elements having round or oval nuclei. The cell contents are very dense in both. To bring out the structure of these elements more clearly some microtome sections, cut transversely through the scutellum of an eight-days' seedling and passing through its main bundle almost longitudinally, were treated with Schultze's solution. No sieve-plates could be found in the elements marked $s, s$, but we have little doubt that they represent young sieve-tubes. As the conducting system of the scutellum must be most active early in the life of the seedling, that is during the period when it depends on the endosperm for the whole of its food-supply, perhaps the differentiation of the sieve-tubes may never proceed further. The shorter elements may represent companion-cells.

Ramifications of various size are given off from the main bundle throughout its course, except for a short distance above the junction with the plumular bundles. In following the bundle-system upwards we find that branches are given off much more freely as we approach the apex. Even the largest are slender as compared with the trunk. The position of the latter shifts somewhat as it nears the apex. It moves from the ventral to the dorsal side of the scutellum, but never approaches the dorsal surface very closely (Fig. I6).

The longer branches are commonly inserted on the lateral faces of the bundle-trunk and extend into the wings of the scutellum. They give off short branchlets towards its dorsal surface.

The shorter branches are inserted on the dorsal face of the bundletrunk and spread out towards the dorsal epithelium, showing in transverse section like the sticks of a fan (Figs. I6, I7). As the scutellum narrows towards the apex these short branches become more numerous, and a fairly thick radial section through the scutellum shows the main bundle feathered on its dorsal face by a close crop of vascular branchlets, all bending outwards (cf. Fig. I). The bundle-trunk terminates in a tuft of such branchlets, which reach almost to the very tip of the scutellum.

Branches and branchlets alike terminate beneath the epithelium of the dorsal surface, generally ending two or three cell-rows below it (Figs. I7, I8). Their insertion on the dorsal and lateral faces of the bundle-trunk modifies 
the structure of the latter. Xylem elements creep round its circumference in order to reach the point from which a branch is given off. In the upper part of its course, where branches are frequent, this leads to the formation of a complete girdle of xylem round the phloem of the bundle-trunk (Figs. I6-I8). Its structure in this region is that which Professors Strasburger and Jeffrey call amphivasal, though near the base it is, as we have seen, collateral with a compact group of xylem on the ventral side (Fig. I5).

The larger branches are also amphivasal as a rule (Figs. I6-I8), but the girdle of xylem is commonly incomplete in the branchlets. The minute structure of two branchlets is shown in Figs, 20 and 2I, both drawn from the same section. The xylem consists of completely lignified tracheids ( $x$, Fig. $2 \mathrm{I})$; the phloem of rather long cells with dense contents and large nuclei, and a few much elongated elements, narrow and almost empty (c.c. in Figs. 20 and $2 \mathrm{I}$ ). These form a core to the branchlet. We have called them central cells.

The structure of the branchlets recalls the transfusion tissue described in the rootlets of Stigmaria by Professor F. E. Weiss. We have adopted the term albuminoid cell for the thin-walled phloem elements with thick contents (alb., Fig. 20). They are seen in the larger branches to be the direct continuation of the phloem in the bundle-trunk (Figs. I6-I8).

\section{CONCLUSION.}

The scutellum of Zea Maïs is distinguished by the presence of glands on its dorsal face, and by the transfusion tissue connected with its vascular system. Both these features are undoubtedly connected with its prolonged function as a sucking organ.

We have found neither glands nor transfusion tissue in the scutellum of Triticum, Hordeum, or Avena, but in these grasses the endosperm is floury and less copious than in $Z e a$, and it becomes semifluid so soon as germination begins. Its reserve of food is exhausted in a few days, and the whole fruit is then cast off by the seedling which in future shifts for itself. Thus the scutellum acts as a sucking organ for a short time only, and it has to deal with a floury endosperm which is already half dissolved by the action of the water absorbed in germination.

The endosperm of Zea, on the contrary, is mainly horny, and is absorbed and dissolved by degrees. Sachs's well-known figure, which we have reproduced with some modification in Fig. I, shows that part of the endosperm is floury, and in this part digestion probably begins.

It is a significant fact that the floury endosperm as shown in such a section is in contact with that region of the scutellum-surface in which glands are most frequent. Possibly their presence there indicates the 
activity of the digestive process during the early stages of germination ${ }^{1}$. For on the one hand the convoluted surface of epithelium in the median zone of the scutellum must secrete a larger quantity of enzyme per unit of endosperm surface than the almost plane face of the scutellum near its apex, and on the other this extra supply of enzyme attacks the more digestible portion of the endosperm and rapidly exhausts it. This is well illustrated in the section of a seed which has begun to germinate: the region of empty cells has at one stage much the same outline as the floury endosperm of the dry seed, though a narrow band of exhausted tissue accompanies the scutellum to its very apex.

If this explanation be true, the floury endosperm is digested very soon after germination by the activity of the highly developed epithelium which borders on it. In this way an immediate supply of food is obtained for the growing embryo while it is producing assimilating organs. The later supply is less liberal, since it is procured by the gradual action of enzyme on the horny endosperm, which is more difficult of digestion and also lies further from the secreting epithelium.

Another member of the Maydeae, Coix Lachryma-Fobi, which has a fruit similar in structure to that of the Maize, likewise possesses glands in the epithelium of the scutellum, but they are less well-developed.

The position of the transfusion tissue in the upper part of the scutellum is difficult to understand. Nor is the function of the numerous xylem elements within that tissue clear. The albuminoid cells no doubt serve to convey the proteids from the dorsal tissues of the scutellum to other parts of the embryo. Possibly the tracheids which are lignified so early in the branchlets may convey starch in a soluble form; or they may carry water in the opposite direction, and irrigate the secreting epithelium.

Quarry Hill, Reigate. July 29, 1904.

${ }^{1}$ See Reed, H. S., 'A Study of the Enzyme-secreting Cells in the Seedlings of Zea Maïs and Phoenix dactylifera.' Ann. of Bot. vol. xviii, 1904, p. 267. 


\title{
EXPLANATION OF FIGURES IN PLATE V.
}

\author{
Drawn by Miss Robertson to illustrate the paper on the Scutellum of Zea Maïs by herself and \\ Miss E. Sargant.
}

. [Figs. 9, 19, 20, 21 are by Miss E. Sargant.]

The following lettering is used throughout :-h.e., horny part of endosperm. f.e., floury part of endosperm. sc., scutellum. ep., epithelium. $v s$., main vascular trunk of the upper scutellum. $v . s^{\prime}$., one of the vascular strands which ramify in the lower scutellum. cl., coleoptile. $c r$., coleorhiza. $R$., radicle. pl., plumule. $r^{\prime} ., r^{\prime}$. , 'wedging' roots. end., endodermis.

\section{PLATE V.}

Fig. I. Diagram of the grain in radial longitudinal section, founded on the figure in Sachs's Textbook.

Fig. 2. Sketch of a seedling one day old. $\times 5$.

Fig. 3. Same seedling with fruit-coat and seed-coat removed. $\times 5$.

Fig. 4. Sketch of a seedling five days old. $\times 5$.

Fig. 5. Side view of the same seedling. $\times 5$.

Fig. 6. Radial longitudinal section of the same seedling. $\times 5$.

Fig. 7. Diagrammatic transverse section through seedling two days old, showing the position of the rudimentary 'wedging roots.'

Fig. 8. Diagrammatic transverse section through the same seedling, $1 \cdot 3 \mathrm{~mm}$. above the level of the last figure.

Fig. 9. Sketch of seedling $A_{9}$, six days old. Life size.

Fig. Io. Part of seedling $\mathrm{A}_{9}$. Endosperm removed, root and shoot cut short. The dotted lines give level of sections drawn in Figs. $5_{5}$ and $16 . \times 1$.

Fig. II. From seedling $A_{9}$. Trans. sec. of scutellum showing epithelium and a vertical gland, $g_{1} . \quad \times 120$.

Fig. I 2. From seedling $A_{9}$. Trans. sec. of scutellum showing gland $g_{2}$ cut obliquely. $\quad \times \quad$ I 20.

Fig. I 3. From embryo dissected from a dry seed and fixed in meth. sp. Trans. sec. of scutellum showing deep pit filled with secretion and prolonged into gland. $\times$ I 37.

Fig. I4. From seedling $\mathrm{A}_{4}$. Trans. sec. of scutellum showing epithelium and two deep vertical glands $\left(g^{\prime}, g^{\prime \prime}\right) . \quad \times \mathrm{I} 20$.

Fig. I 5. From seedling $A_{9}$. Main bundle of scutellum. $\times$ I 37.

Fig. 16. From seedling $A_{9}$. Complete trans. sec. of scutellum. The main bundle is cut at a higher level than that drawn in Fig. I5 (see Fig. 10); its structure has become amphivasal, and it is giving off ramifications resembling transfusion tissue. $\times 33$ circa.

Fig. I 7. From seedling $A_{9}$. Part of section drawn in Fig. 16 , enlarged to show the main bundle and its immediate ramifications. $\times 125$.

Fig. I8. From seedling $\mathbf{A}_{4}$. Amphivasal structure of main bundle and single ramification with its termination. $\times 125$.

Fig. 19. From seedling $\mathrm{A}_{1}^{\prime}$ (just germinated). Part of phloem from radial long. sec. $\times 240$. s.s., probably young sieve-tubes.

Fig. 20. From seedling $\mathrm{A}_{9}$ (six days old). Phloem from branchlet cut longitudinally, alb. albuminoid cells. c.c., central cells.

Fig. 2 I. From seedling $\mathrm{A}_{9}$; same section as above. Branchlet cut transversely : $x$, xylem: $a l b$, albuminoid cells : c.c., central cells. 
Annals of Botany

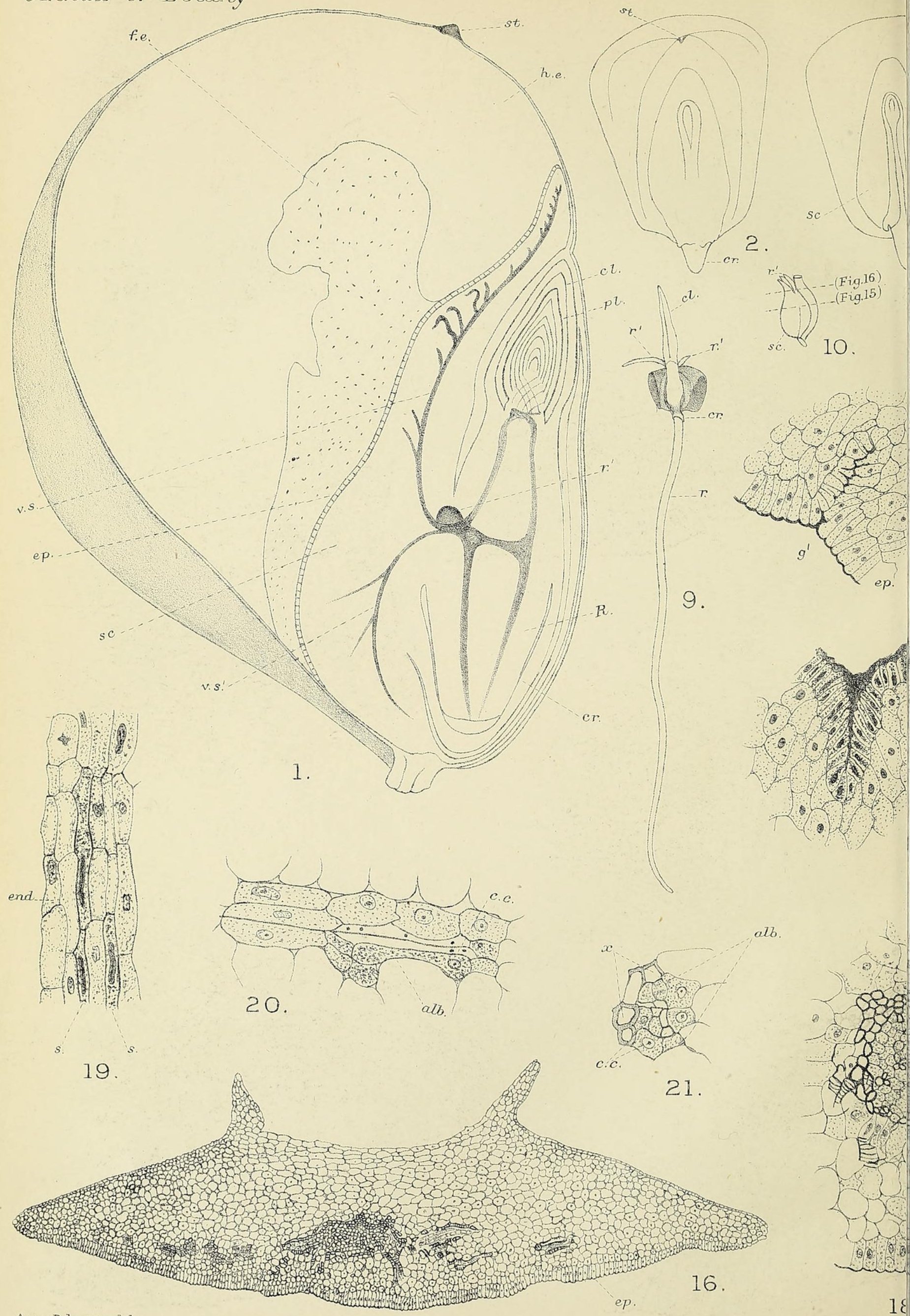


Annals of Botany
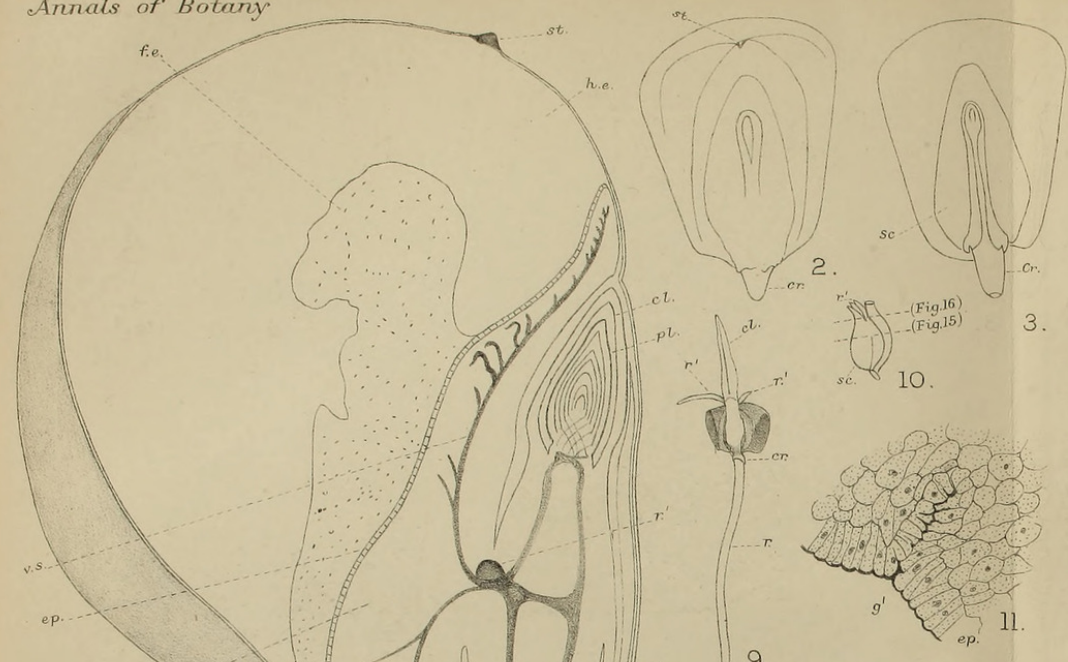

9.

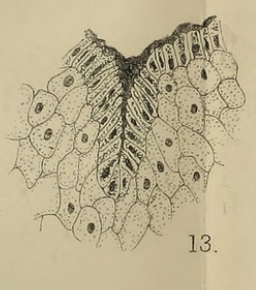

alb
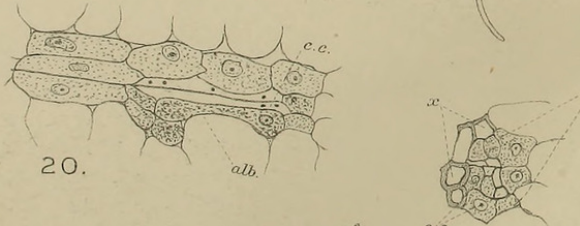

21

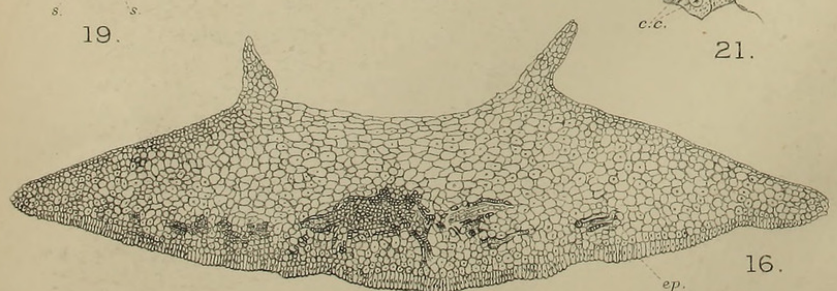

SARGANT \& ROBERTSON - ZEA MAIS.

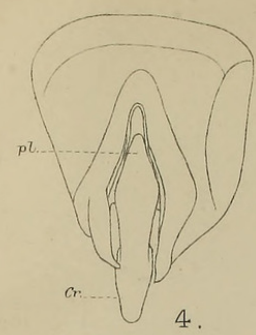

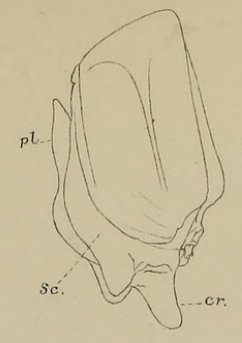

5.
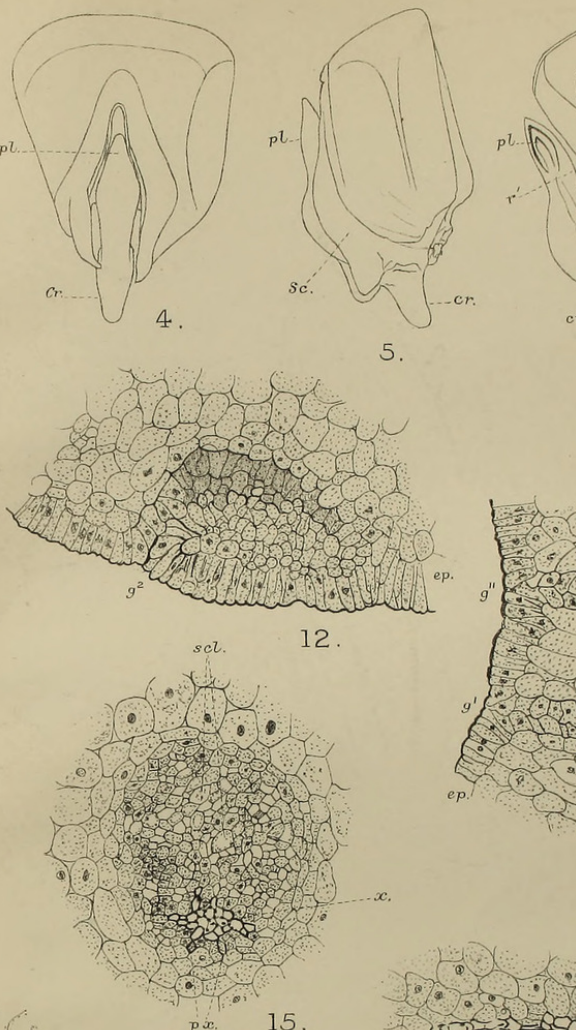

Vol.XIX,Pl.T.

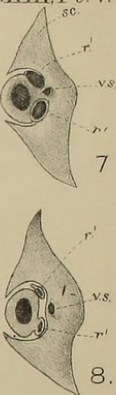

alb.

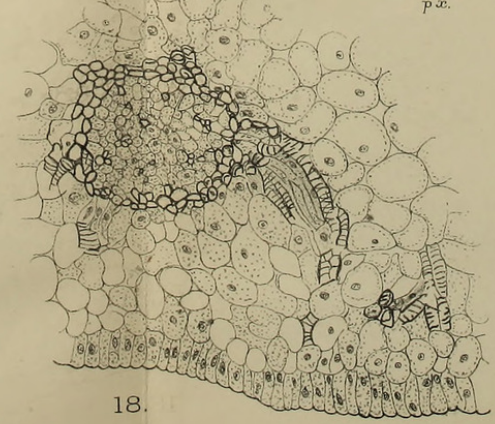

12

15.

\section{F}

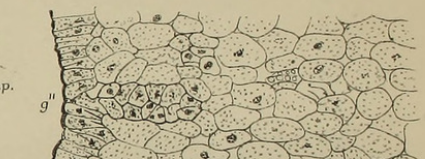

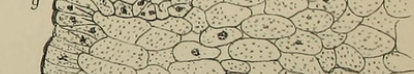

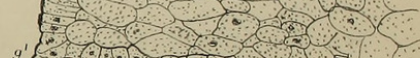
$8+1 \cdot 1 \cdot \ldots$

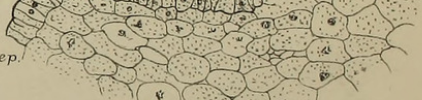

14

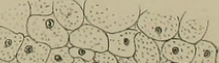

(1)

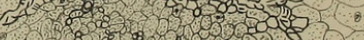

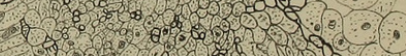

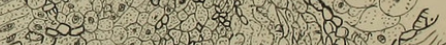
1. 3. .

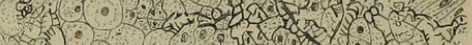

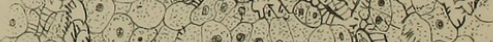
$\therefore 0 \% \div 0$

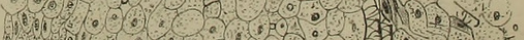

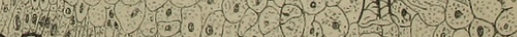

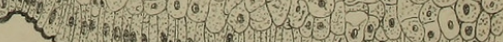
17. 


\section{$2 \mathrm{BHL}$ Biodiversity Heritage Library}

Sargant, Ethel and Arber, Agnes Robertson. 1905. "The anatomy of the scutellum in Zea maïs." Annals of botany 19, 115-123. https://doi.org/10.1093/oxfordjournals.aob.a088986.

View This Item Online: https://www.biodiversitylibrary.org/item/233541

DOI: https://doi.org/10.1093/oxfordjournals.aob.a088986

Permalink: https://www.biodiversitylibrary.org/partpdf/318788

\section{Holding Institution}

Smithsonian Libraries

\section{Sponsored by}

Biodiversity Heritage Library

\section{Copyright \& Reuse}

Copyright Status: Not in copyright. The BHL knows of no copyright restrictions on this item.

This document was created from content at the Biodiversity Heritage Library, the world's largest open access digital library for biodiversity literature and archives. Visit BHL at https://www.biodiversitylibrary.org. 